\title{
Did the COVID-19 Pandemic Makes Scientists Forget 'Primum Non-Nocere', One of the Most Important Principles Of Bioethics?
}

\author{
Karaosmanoglu HK* \\ Bakirkoy Dr. Sadi Konuk Training and Research Hospital Infectıous Diseases and Clinical \\ Microbiology, Turkey
}

*Corresponding author: Hayat Kumbasar Karaosmanoglu, Adress: Bakırkoy Dr. Sadi Konuk Training and Research Hospital Infectıous Diseases and Clinical Microbiology, Istanbul, Turkey,

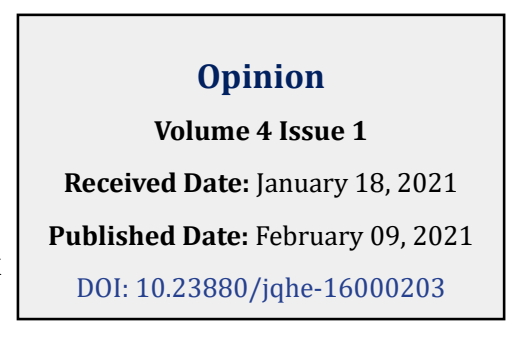
Tel: +90 50645392 40; E-mail: drhayat1@hotmail.com

\section{Opinion}

The famous Latin phrase, the origin is uncertain "Primum non-nocere (first, no harm)" is one of the principal precepts of bioethics that all students are taught in medical schools and is a fundamental principle world [1]. Another way to put it is that "given the current problem, not doing anything, or even doing nothing, maybe better than risking harm than good. It reminds the medical staff to consider the potential harm any intervention can cause. The use of an intervention that carries a clear risk of damage but a less specific chance of benefit is invoked when discussed .

The novel coronavirus (CoV)-2019 pandemic has become a substantial public health challenge. The virus was identified as SARS CoV-2, and the disease caused by this virus is named CoV disease-2019 (COVID-19). Even though most patients are asymptomatic, in many patients, COVID-19 manifests into pneumonia, acute respiratory distress syndrome (ARDS), septic shock, and death [2,3]. Unfortunately, there is currently no fully proven treatment for severe cases other than corticosteroids. In this challenging process, nonevident-based medical applications have entered our life. The useful patient rescue of physicians and scientists, who does not know what to do with a panic, maybe resulted in adverse situations. Sometimes scientists 'and even more so governments' race for science and their enthusiasm for being firsts also provided a basis for disregarding this basic principle. Even the internationally reputable treatment guidelines recommended that FDA approved drugs are not recommended after a while as the studies accumulate during the pandemic process. We have witnessed evidence that they are even harmful. For example, with a single RCT [4], we see that even steroids, whose efficacy is proven in short-term and low doses and only in severe disease and that we know for many years are not innocent at all, are used very widely and carelessly. We have been experienced in viral infections for long years. We have been subject to negative results of using corticosteroids, so prepared and thought that we have been operating in most cases in viral infections. Likewise, it is also evident that all immunosuppressives, including the IL6 inhibitors, shown not to affect mortality in recent studies, are administered to many patients without being thoroughly examined, planning long-term follow-ups, and not being selected correctly. We see that promising antivirals, especially remdesivir and hydroxychloroquine, have also been published, which have resulted in disappointment after uncontrolled use too many patients, and those who were not recommended Blinded Manuscript later joined the caravan. Although the development of secondary bacterial infection in COVID-19 has been shown at a shallow rate by many studies, the widespread use of irrational antibiotics in the world is another problem. It should not be considered that the use of these unconscious antibiotics may also be a public health problem that may be a bigger public health problem in the future, even more than the COVID-19 pandemic.

In the COVID-19 pandemic, which has the world under the effect of multilateral (Social, economic, political, etc), science is also under the impact of politics and preparing the ground for wrong directions. Articles in which science is used in politics are also interesting recently. Yet science must be far from politics, much freer and much more honest. So, in this case, should we be a little more careful and cautious in using agents that will bring many toxicities with them? What about after that? After all our experiences and learning over one year, but there are still many unanswered questions, will we continue in the same way? In fact, over time, science 
will give the answers to the ongoing confusion and all these unanswered questions.

\section{Conclusion}

The most crucial principle taught in medical ethics is "Primum non-nocere (first, no harm)" and we science people look like we forget that long during the pandemic process. Avoiding harm to patients and science, scientists' efforts for centuries, and the experiences gained should be one of the principles of fighting the pandemic. It should be all scientists' duty to apply the rational drug use strategies recorded as an essential stage in recent years, even with the pandemic process, and expose effort for it. Management of the pandemic is more challenging; it will be more rational to apply the treatments that may hazard the patients with more

\section{References}

1. Google book search 1800-1970.

2. Guo YR, Cao QD, Hong ZS, Tan YY, Chen SD, et al. (2020) The origin, transmission and clinical therapies on coronavirus disease 2019 (COVID-19) outbreak: an update on the status. Mil Med Res 7(1): 1-10.

3. Guan W, Ni Z, Hu Y, Liang WH, Ou CQ, et al. (2020) Clinical characteristics of coronavirus disease 2019 in China. N Engl J Med 382(18): 1708-1720.

4. Recovery Collaborative Group (2020) Dexamethasone in Hospitalized Patients with Covid-19 - Preliminary Report. N Engl J Med. 